\title{
RANCANG BANGUN ALAT DEHYDRATOR BIOETANOL UNTUK MENGHASILKAN FUEL GRADE ETHANOL (FGE)
}

\author{
Rochmad Winarso \\ Fakultas Teknik, Program Studi Teknik Mesin \\ Universitas Muria Kudus \\ Email: boswin2001@gmail.com \\ Bahtiar Setya Nugraha \\ Fakultas Teknik, Program Studi Teknik Mesin \\ Universitas Muria Kudus \\ Email: setyanugraha_72@yahoo.co.id
}

\begin{abstract}
ABSTRAK
Bioethanol merupakan salah satu bahan bakar alternatif dengan sumber bahan baru yang dapat diperbarui. Bioethanol dapat menjadi bahan bakar alternatif bila mempunyai konsentrasi lebih dari $99 \%$ yang dikenal dengan nama Fuel Grade Ethanol. Proses pembuatan Fuel Grade Ethanol menggunakan metode pemisahan lanjut diantaranya adalah dengan metode distilasi azeotrop, pervorasi membran, dan adsorbsi. Tujuan dari penelitian ini adalah melakukan pengujian mesin dehydrator bioethanol yang bekerja dengan metode absorbsi. Mesin dehydrator ini menggunakan zeolit syntetis dengan ukuran 3 A yang sebelumnya telah dikembangkan. Pengembangan ini dilakukan melalui tiga tahapan, yaitu: (1) Tahap perancangan (desain) alat dehydrator biorthanol; (2) Tahap pembuatan alat dehydrator berdasarkan spesifikasi yang telah ditetapkan ; (3) Pengujian alat dehydrator yang berorientasi hasil yaitu bioetanol minimal berkadar sekitar 99\%. Mesin destilator bioetanol yang telah dikembangkan mempunya spesifikasi sebagai berikut: dimensi tangki bahan baku tingginya adalah $250 \mathrm{~mm}$ dengan diameter 300 $\mathrm{mm}$, Bagian tabung I terbuat dari pipa stainless steel dengan diameter $100 \mathrm{~mm}$ dan tinggi $600 \mathrm{~mm}$. Tebal dari pipa tersebut adalah $2 \mathrm{~mm}$. Tabung II terbuat dari stainless steel yang mempunyai diamater $100 \mathrm{~mm}$ dan tinggi $300 \mathrm{~mm}$ dengan ketebalan $2 \mathrm{~mm}$. Kondensor berdiameter $100 \mathrm{~mm}$ dan tinggi $600 \mathrm{~mm}$. Hasil penelitian ini menunjukkan bahwa mesin yang sudah dikembangkan ini mampu menghasilkan Fuel Grade Ethanol dengan kadar lebih dari 99\%.
\end{abstract}

Kata kunci: dehydrator, bioethanol, fuel grade ethanol, bahan bakar alternatif.

\begin{abstract}
Bioethanol is one of the alternative fuels with new sources of renewable materials. Bioethanol can be an alternative fuel when a concentration of more than 99\%, known as Fuel Grade Ethanol. Fuel Grade Ethanol making processes using advanced separation methods such as by azeotropic distillation method, the sprocket membrane and adsorption. The purpose of this study was to test bioethanol dehydrator machine that works with the absorption method. This dehydrator machine using zeolite syntetis with a size of 3 A that had been previously developed. This development is done through three stages, namely: (1) Phase design (design) tool biorthanol dehydrator; (2) Stage of dehydrator tool based on established specifications; (3) Testing dehydrator result-oriented tool that bioethanol yield of at least about 99\%. Bioethanol distillation machines which have been developed possessed the following specifications: dimensions of the tank material is $250 \mathrm{~mm}$ high with a diameter of $300 \mathrm{~mm}$, Part I tube is made of stainless steel pipe with a diameter of $100 \mathrm{~mm}$ and a height of $600 \mathrm{~mm}$. Thickness of the pipe is 2 $\mathrm{mm}$. II tube is made of stainless steel having a diameter of $100 \mathrm{~mm}$ and a height of $300 \mathrm{~mm}$ with a thickness of $2 \mathrm{~mm}$. Condenser diameter of $100 \mathrm{~mm}$ and a height of $600 \mathrm{~mm}$. These results indicate that the engine that has been developed is capable of producing Fuel Grade Ethanol with levels over 99\%.
\end{abstract}

Keywords: dehydrator, bioethanol fuel grade ethanol, alternative fuels.

\section{PENDAHULUAN}

Bioetanol $(\mathrm{C} 2 \mathrm{H} 5 \mathrm{OH})$ merupakan salah satu bahan bakar alternatif dengan sumber bahan baru yang dapat diperbarui. Bioethanol dapat dihasilkan dari berbagai macam bahan baku yang banyak terdapat di Indonesia sehingga sangat potensial untuk diolah dan dikembangkan karena bahan bakunya sangat 
dikenal masyarakat. Tumbuhan yang potensial untuk menghasilkan bioetanol antara lain tanaman yang memiliki kadar karbohidrat tinggi, seperti: tebu, nira, aren, sorgum, ubi kayu, jambu mete (limbah jambu mete), garut, batang pisang, ubi jalar, jagung, bonggol jagung, jerami dan bagas [1]

Bioetanol berwujud cairan yang dihasilkan dari proses fermentasi gula dari sumber karbohidrat dengan bantuan mikroorganisme. Bahan baku pembuatan bioetanol ini dibagi menjadi tiga kelompok yaitu: bahan sukrosa (nira, tebu, nira nipah, nira sargum manis, nira kelapa, nira aren, dan sari buah mete), bahan berpati (bahan yang mengandung pati atau karbohidrat seperti tepung ubi, tepung ubi ganyong, sorgum biji, jagung, cantel, sagu, ubi kayu, ubi jalar, dan lain-lain, dan bahan berselulosa/lignoselulosa (tanaman yang mengandung selulosa /serat seperti kayu, jerami, batang pisang, dan lain-lain [2].

Penggunaan bioetanol sebagai campuran BBM dapat mengurangi emisi karbon monooksida dan asap lainnya dari kendaraan. Hal ini sudah dibuktikan oleh beberapa negara yang sudah lebih dulu mengaplikasikannya, seperti Brazil dan Jepang. Perkembangan bisnis bioetanol di Indonesia seharusnya juga bisa menyamai kedua negara tersebut. Dengan melimpahnya bahan baku, seharusnya kita bisa menggantikan sebagian pemakaian BBM yang sudah semakin langka dengan bioetanol. Selain untuk bahan bakar (Fuel Grade Ethanol), Bioethanol dapat digunakan untuk industri kimia, farmasi, kedokteran, kosmetik, bahan baku aneka minuman, dll [3]

Proses pembuatan bioethanol dengan bahan baku ketela pohon dilaksanakan dengan 4 tahapan yaitu tahap persiapan bahan baku, tahap likuifikasi, tahap sakarifikasi, tahap destilasi dan tahap dehidrasi. Tahap persiapan bahan baku merupakan tahap awal yang terdiri dari proses pengupasan ketela pohon, pencucian dan pemarutan ketela pohon dan proses perebusan ketela pohon. Tahapan berikutnya adalah proses likuifikasi yaitu proses mencairkan kembali larutan ketela tersebut setelah mengental. Proses likuifikasi tersebut menggunakan enzym alfa amilasi pada temperatur 900C sampai 950C. Proses likuifikasi tersebut dilaksanakan selama 2 jam. Tahap berikutnya adalah tahap sakarifikasi yaitu penambahan enzym gluco amylase pada larutan ketela pada suhu 600C sampai dengan 66 0C. Tahap berikutnya adalah proses fermentasi yang bertujuan untuk mengkonversi glukosa (gula) menjadi etanol dan $\mathrm{CO} 2$, dengan mencampurkan Ragi (yeast) kedalam larutan ethanol pada suhu ruang. Tahap berikutnya adalah proses distilasi untuk memisahkan alkohol dari broth dengan pemanasan pada suhu 78 oC yang akan menguapkan alkohol menuju ke kondensor. Setelah itu dilanjutkan dengan proses distilasi dengan alat distilator sehingga mendapatkan bioethanol dengan kadar lebih dari 90\%. Bioethanol dengan kadar $90 \%$ ini belum dapat digunakan sebagai bahan bakar karena kandungan airnya masih cukup tinggi. Oleh karena itu bioethanol dengan kadar 90\% ini perlu dikeringkan lagi dengan mesin dehydrator sehinnga didapat bioethanol dengan kadar minimal 99\% yang disebut dengan Fuel Grade Bioethanol. Diagram alir proses pembuatan bioethanol sebagaimana gambar 1 .

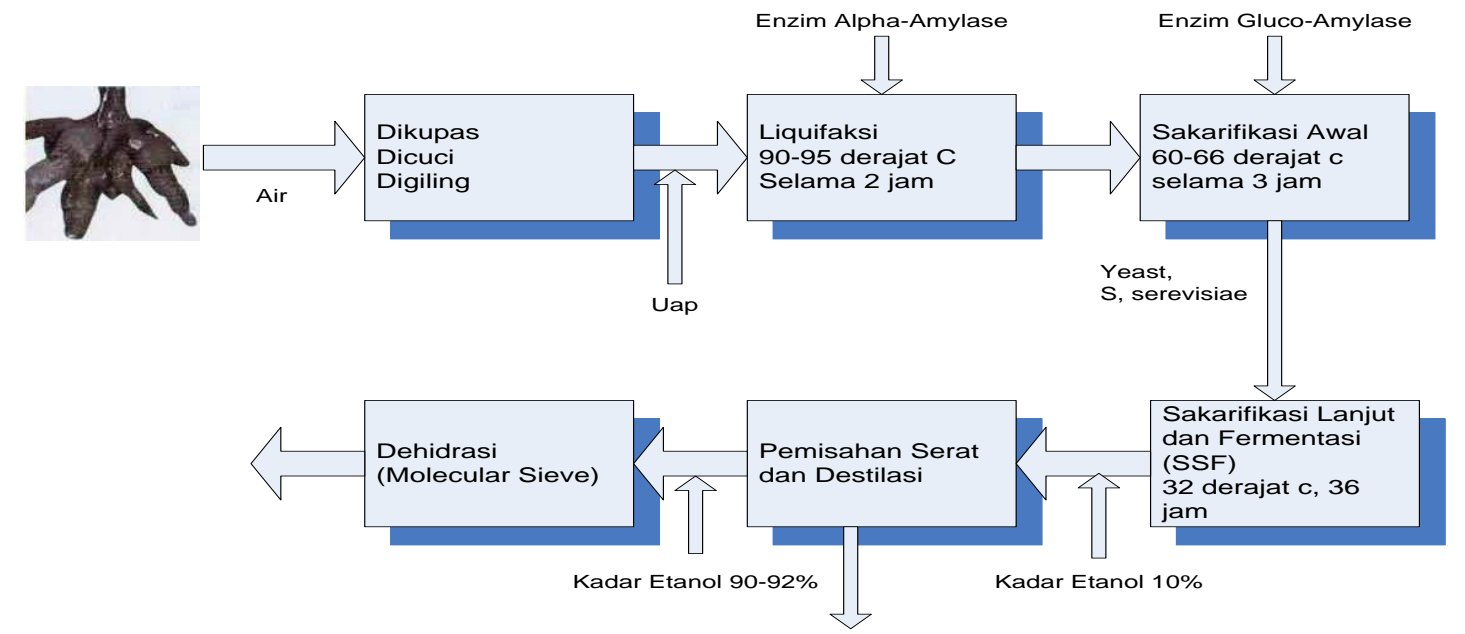

Gambar 1. Diagram Alir Pembuatan Bioethanol

Fuel grade ethanol adalah alkohol murni yang bebas air (anhydrous alcohol) dan berkadar lebih dari 99,5\%. Penggunaan bioetanol sebagai bahan bakar kendaraan bermotor bervariasi antara blend hingga bioetanol murni. Bioetanol sering disebut dengan notasi "Ex", dimana $\mathrm{x}$ adalah persentase kandungan bioetanol dalam bahan bakar. Beberapa contoh penggunaan notasi "Ex" antara lain:

1. E100, bioetanol $100 \%$ atau tanpa campuran

2. E85, campuran $85 \%$ bioetanol dan bensin $15 \%$

3. E5, campuran $5 \%$ bioetanol dan bensin $95 \%$ 
Bioetanol dengan kandungan 100\% memiliki nilai oktan (octane) RON 116 - 129, yang relatif lebih tinggi dibandingkan bahan bakar premium dengan nilai oktan RON 88. Karena nilai oktan yang tinggi, bioetanol dapat digunakan sebagai pendongkrak oktan (octane booster) untuk bahan bakar beroktan rendah. Nilai oktan yang lebih tinggi pada bioetanol juga berpengaruh positif terhadap efisiensi dan daya mesin [4].

Tujuan dari penelitian ini adalah melakukan rancang bangun mesin dehydrator bioethanol yang mampu menghasilkan Fuel Grade Ethanol dengan menggunakan zeolit sintetis sebagai absorben.

\section{BAHAN DAN METODE}

Rancang bangun mesin ini dilakukan melalui tiga tahapan, yaitu: (1) Tahap perancangan (desain) alat dehydrator biorthanol; (2) Tahap pembuatan alat dehydrator berdasarkan spesifikasi yang telah ditetapkan ; (3) Pengujian alat dehydrator yang berorientasi hasil yaitu bioetanol minimal berkadar sekitar $99 \%$

Tahap satu yaitu tahap perancangan alat dehydrator, dilakukan kegiatan sebagai berikut: Mendesain bentuk, dimensi dan material yang digunakan untuk tangki pengisian bahan baku model bath dengan kapasitas 10 liter. Mendesain bentuk, dimensi dan material yang digunakan untuk kolom dehydrasi dua tingkat dengan kapasitas zeolyt syntetis seberat $5 \mathrm{~kg}$. Mendesain bentuk, dimensi dan material yang digunakan untuk kondensor. Mendesain bentuk, dimensi dan material yang digunakan untuk rangka penopang. Tahap dua yaitu tahap pembuatan alat dehydrator, dilakukan kegiatan sebagai berikut: Melakukan proses pembuatan dehydrator sesuai dengan spesifikasi yang sudah ditetapkan melalui proses permesinan (pemotongan, pembentukan, penyambungan, perakitan dan finishing). Tahap tiga yaitu pengujian alat dehydrator hasil pengembangan yang berorientasi hasil yaitu bioetanol minimal berkadar sekitar 99\% dilakukan kegiatan sebagai berikut:

Bahan bahan yang digunakan dalam penelitian ini adalah Bioethanol berkadar $93 \%$ hasil dari proses destilasi. Absorben yang digunakan adalah Zeolit sintetis dengan ukuran 3 Angstrom. Alat yang digunakan adalah mesin dehydrator yang telah selesai dibuat dengan bentuk dan dimensi sebagaimana gambar 2 .
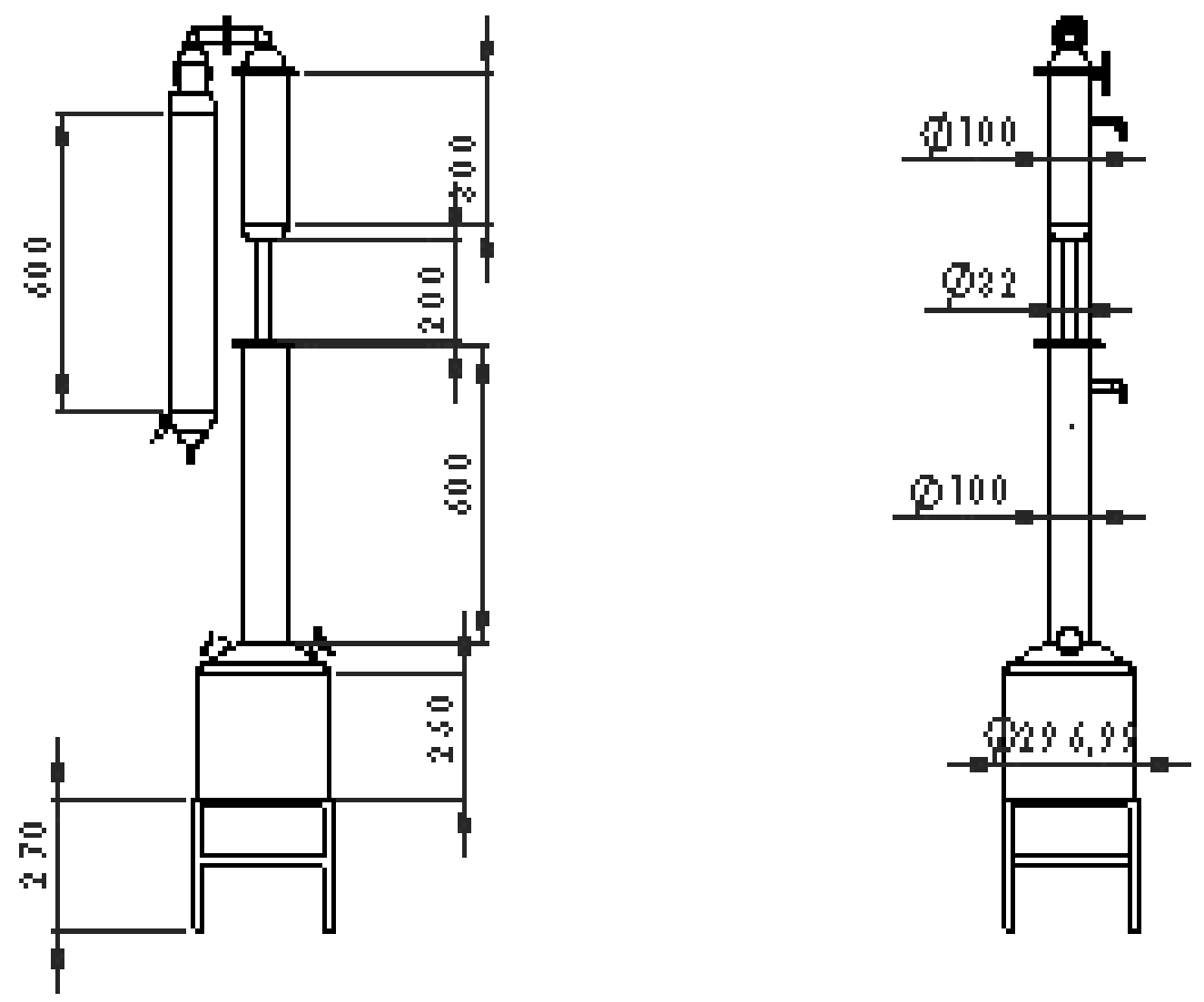

Gambar 2. Mesin Dehydrator Bioethanol 
Proses pengujian dilakukan dengan tahapan sebagai berikut: memasang regulator gas elpiji dan memastikan tidak ada kebocoran gas. Setelah itu memasang selang "A" dari tabung kondensor ke output pompa air (otomatis). Dan kemudia memasang dan menempatkan selang "B" diatas drum plastik dekat pompa air. Dilanjutkan dengan membuka kran pada pompa air, lalu menyalakan pompa. Biarkan air mengalir dari drum ke kondensor dan balik lagi ke drum melalui selang "B". Setelah itu mematikan kran, sampai pompa mati dengan sendirinya (otomatis). Pastikan tidak ada kebocoran air pada tiap sambungan selang di tabung kondensor. Memasukan 5 liter atau 10 liter bahan ethanol kadar 90-92 \% ke dalam tangki, lalu menutup kencang menggunakan kunci pengencang. Menyalakan kompor, untuk awal pemanasan agak besar apinya. Selang 15-20 menit, ketika jarum termometer "B" mulai naik, segera kecilkan api kompor, lalu buka kran pompa air 1/2 sampai 3/4-nya. Ethanol akan mulai keluar dari output tabung kondensor, mempertahankan posisi suhu pada termometer sekitar $55-57^{\circ} \mathrm{C}$. Di suhu tersebut kadar ethanol akan $99-100 \%$. Pada akhir waktu penyulingan, suhu akan berkisar di $60-62^{\circ} \mathrm{C}$. Di suhu ini, kadar ethanol akan sedikit menurun sekitar $97-98^{\circ} \mathrm{C}$.

Proses pengujian dilaksanakan sebanyak dua kali dengan data sebagai berikut:

$\begin{array}{ll}\text { Pengujian I } & \\ \text { Bahan ethanol } 92 \% & : 10 \text { liter } \\ \text { Banyak Zeolit } & : 5 \mathrm{~kg} \\ \text { Lama pemanasan awal } & : 18-20 \text { menit } \\ & \\ \text { Pengujian II } & : 6 \text { liter } \\ \text { Bahan ethanol } 92 \% & : 3 \mathrm{~kg} \\ \text { Banyak Zeolit } & : 10-15 \text { menit } \\ \text { Lama pemanasan awal } & \end{array}$

\section{HASIL DAN PEMBAHASAN}

Proses rancang bangun ini telah mengasilkan propotipe alat distilator bioethanol dengan kapasitas 10 liter. Absorben yang digunakan adalah Zeolit sintetis dengan ukuran 3 Angstrom. Setelah dilaksanakan pengujian pertama didapatkan data data sebagai berikut: Setelah mesin distilator dijalankan selama \pm 20 menit, temperatur di titik B sebesar $57-58^{\circ} \mathrm{C}$ dan dititik A $67-68^{\circ} \mathrm{C}$ mesin menghasilkan bioethanol sebanyak 1 liter dengan kadar $100 \%$. Setelah mesin distilator dijalankan selama \pm 20 menit berikutnya, temperatur di titik B sebesar $57-58^{\circ} \mathrm{C}$ dan dititik A $67-68^{\circ} \mathrm{C}$ mesin menghasilkan bioethanol sebanyak 1 liter dengan kadar $100 \%$. Setelah mesin distilator dijalankan selama \pm 20 menit berikutnya, temperatur di titik B sebesar $57-58^{\circ} \mathrm{C}$ dan dititik A $67-68^{\circ} \mathrm{C}$ mesin menghasilkan bioethanol sebanyak 1 liter dengan kadar $100 \%$. Setelah mesin distilator dijalankan selama \pm 20 menit berikutnya, temperatur di titik B sebesar $57-58^{\circ} \mathrm{C}$ dan dititik A $67-68^{\circ} \mathrm{C}$ mesin menghasilkan bioethanol sebanyak 1 liter dengan kadar 100 $\%$. Setelah mesin distilator dijalankan selama \pm 20 menit berikutnya, temperatur di titik B sebesar 57$58^{\circ} \mathrm{C}$ dan dititik A $67-68^{\circ} \mathrm{C}$ mesin menghasilkan bioethanol sebanyak 1 liter dengan kadar $100 \%$. Setelah mesin distilator dijalankan selama \pm 20 menit berikutnya, temperatur di titik B sebesar $59^{\circ} \mathrm{C}$ dan dititik A $68-69^{\circ} \mathrm{C}$ mesin menghasilkan bioethanol sebanyak 1 liter dengan kadar $100 \%$. Setelah mesin distilator dijalankan selama \pm 20 menit berikutnya, temperatur di titik B sebesar $60^{\circ} \mathrm{C}$ dan dititik A $69-70^{\circ} \mathrm{C}$ mesin menghasilkan bioethanol sebanyak 1 liter dengan kadar $100 \%$. Setelah mesin distilator dijalankan selama \pm 20 menit berikutnya, temperatur di titik B sebesar $60^{\circ} \mathrm{C}$ dan dititik A $69-70^{\circ} \mathrm{C}$ mesin menghasilkan bioethanol sebanyak 1 liter dengan kadar $100 \%$. Dan setelah mesin distilator dijalankan selama \pm 20 menit berikutnya, temperatur di titik B sebesar $62^{\circ} \mathrm{C}$ dan dititik A $72-79^{\circ} \mathrm{C}$ mesin menghasilkan bioethanol sebanyak 1 liter dengan kadar $100 \%$. Hasil lengkap pengujian sebagaimana Tabel 1. 
Tabel 1. Hasil pengujian yang dilakukan

\begin{tabular}{ccccc}
\hline \multirow{2}{*}{$\begin{array}{c}\text { Waktu } \\
\text { (Menit) }\end{array}$} & \multicolumn{2}{c}{ Temperatur (OC) } & \multicolumn{2}{c}{ Hasil } \\
\cline { 2 - 5 } & $\begin{array}{c}\text { Titik } \boldsymbol{A} \\
\text { (Tangki) }\end{array}$ & $\begin{array}{c}\text { Titik B } \\
\text { (Kondensor) }\end{array}$ & Kadar (\%) & $\begin{array}{c}\text { Vol } \\
(\text { Liter) }\end{array}$ \\
\hline 20 & $67-68$ & $57-58$ & 100 & 1 \\
40 & $67-68$ & $57-58$ & 100 & 1 \\
60 & $67-68$ & $57-58$ & 100 & 1 \\
80 & $67-68$ & $57-58$ & 100 & 1 \\
100 & $67-68$ & $57-58$ & 100 & 1 \\
120 & $67-68$ & $58-59$ & 100 & 1 \\
140 & $69-70$ & $59-60$ & 100 & 1 \\
160 & $69-70$ & $59-60$ & 99,5 & 1 \\
180 & $70-78$ & $60-61$ & 98 & 1 \\
& & & 99,72 & 9 \\
\hline
\end{tabular}

\section{KESIMPULAN}

Dari hasil penelitian ini dapat disimpulkan bahwa telah dikembangkan alat dehydrator bioethanol dengan spesifikasi sebagai berikut: diameter tangki $300 \mathrm{~mm}$, tinggi tangki $250 \mathrm{~mm}$, terbuat dari bahan stainles steel A304 dengan ketebalan $2 \mathrm{~mm}$. Bagian tabung I terbuat dari pipa stainless steel dengan diameter $100 \mathrm{~mm}$ dan tinggi $600 \mathrm{~mm}$. Tebal dari pipa tersebut adalah $2 \mathrm{~mm}$. Tabung II terbuat dari stainless steel yang mempunyai diamater $100 \mathrm{~mm}$ dan tinggi $300 \mathrm{~mm}$ dengan ketebalan $2 \mathrm{~mm}$. Kondensor dirancang berdiameter $100 \mathrm{~mm}$ dan tinggi $600 \mathrm{~mm}$. Berdasarkan hasil pengujian yang dilakukan menunjukkan bahwa mesin dehydrator tersebut mampu menghasilkan bioethanol berkadar 99,72\%.

\section{UCAPAN TERIMA KASIH}

Ucapan terima kasih terutama ditujukan Direktorat Pendidikan Tinggi yang telah mendanai penelitian ini. Ucapan terima kasih dapat juga disampaikan kepada pihak Universitas Muria Kudus yang membantu pelaksanaan penelitian.

\section{DAFTAR PUSTAKA}

[1] Hambali, Eliza, dkk, 2007, Teknologi Bioenergi, Jakarta, ArgoMedia Pustaka Putra, P, Y, D, 2010, Analisa perbandingan unjuk kerja motor berbahan bakar premium dan campuran premium bioethanol (BE30, BE50, BE70, BE90),Fakultas Teknik, Universitas Panca Sakti, Tegal.

[2] Puji Lestari, dkk, 2007, Pengaruh Penggunaan Bahan Bakar Bioetanol Terhadap Emisi Gas Buang Kendaraan Bermotor Mesin Bensin (otto) Pada Siklus Urban (UC) dan Ekstra Urban (EUC), Departemen Teknik Lingkungan dan Teknik Mesin, Institut Teknologi Bandung (ITB), BandungWei-Dong Hsieh, Rong;Hong Chen, Tsung;Lin Wu, Ta;Hui Lin, Engine Performance and Pollutant Emission of an SI Engine Using EthanolD Gasoline Blended Fuels, Atmospheric Environment 2002; $36: 403 ; 410$

[3] Andriko D, haholongan, 2009, Uji Eksperimental Perbandingan Unjuk kerja Motor Bakar Berbahan Bakar Primium Dengan Campuran Premium-bioetanol (Gasohol BE-35 Dan BE-40), Departemen Teknik Mesin, Fakultas Teknik, Universitas Sumatra Utara, MedanSusilo, Sigit, 2009, Rancangan dan uji kinerja alat distilasi etanol dengan metode rektifikasi, Departemen Teknik Pertanian, Institut Pertanian Bogor, Bogor. 
[4] Devanta Bayu Prasetyo, Fajar Patriayudha, Pemakaian Gasohol sebagai Bahan Bakar Pada Kendaraan Bermotor, Jurusan Teknik Kimia, Universitas Diponegoro, Semarang Prasetyo, D, B,dkk, 2009, Pemakaian Gasohol sebagai bahan bakar pada kendaraan, Jurusan Teknik Kimia, Universitas Diponegoro, Semarang. 